\title{
Application of Distortion Reduction in FIR Filters in Dynamic Systems through Computational Methods
}

Sergio Bimbi Junior

Agenor de Toledo Fleury

Ronaldo Ruas

Vitor Chaves de Oliveira 


\title{
Application of Distortion Reduction in FIR Filters in Dynamic Systems through Computational Methods
}

\author{
Sergio Bimbi Junior, Agenor de Toledo Fleury, Ronaldo Ruas, Vitor Chaves de Oliveira \\ São Paulo State Technological Research Institute - IPT \\ Program - Master in Industrial Processes
}

\begin{abstract}
The article shows a development methodology in the operation of finite impulse response (FIR) digital filters when built on computational methods based on general use processors.
\end{abstract}

Key Words- Digital Filter, Digital Signal Processing, Low Pass Filter.

\section{INTRODUCTION}

Digital systems generally contain advantages when compared to analog systems; among those features are elements such as high reliability, flexibility of system upgrades and cost-related issues. In addition to this feature, there is a growing number of applications that use large integration scale technology (4). As a result of many computational applications requiring frequent changes in their functionality or an increase in behavioral flexibility, it is often possible to rapidly built prototypes for digital systems. In this article, we seek to develop an FIR digital filter from a modified Hamming window (1), wherein the computer system is based on a queue where the first elements inserted are the first to be removed (FIFO).

\section{FIR DIGITAL FILTER}

An FIR filter can be represented by Equation 1.

$$
y[k]=\sum_{n=0}^{N-1} \mathrm{~h}[\mathrm{n}] * \mathrm{x}[\mathrm{k}-\mathrm{n}](1)
$$

Where $x$ represents the input signal, $h$ represents the filter coefficients and $y$ is the result, i.e., the filtered output signal. In this implementation, a series of multiply-accumulate (MAC) operations are applied to each sample of the input signal; this occurs by multiplying the $N$ input samples by the system coefficients and finally adding the results for obtaining the output signal (2).

\section{FIFO}

FIFO is a special type of list characterized by how its elements are inserted or removed. In a queue, the first elements inserted are the first to be removed (first in, first out), characterizing the original term FIFO. The architecture of a FIFO structure can be demonstrated in Figure 1.

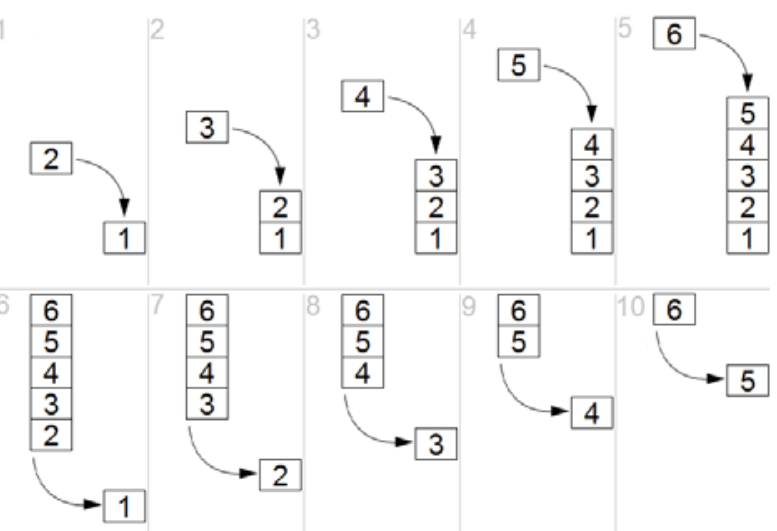

Figure 1. Architecture of a FIFO structure.

\section{SYSTEM ARITHMETIC}

In digital filters, it is possible to develop alternative structures that do not apply the use of multipliers directly. These systems use distributed arithmetic (2), where the sum of products between the filter coefficients and the input signals is made without multipliers. In this way, the hardware is minimized, as well as consumption (6). This technique can be seen in Equation 2.

$y[k]=\sum_{i=0}^{B-1}\left(\sum_{n=0}^{N-1} h(n) * b_{k-n, i}\right) * 2^{-i}+\left(\sum_{n=0}^{N-1} h(n) *-b_{k-n, 0}\right)(2)$

Where $b_{k, i}$ are bits 0 or 1 of signal $x(n)$ represented in two's complements with $(B+1)$ bits and $b_{k, 0}$ the sign bit.

\section{FILTERS HAVING WINDOW}

Digital filters having window apply rejections at undesired points in the system at present lobules, i.e., those that are not acceptable beyond the main lobe. This phenomenon occurs due to having frequencies that are not required for that filter. In the proposed development, the modified Hamming window will be used as seen in equation 3 . 


$$
\begin{gathered}
w[n]=\left[0,54-0,46^{n x-1} \cos \left(\frac{2^{n x-1} \pi n}{M}\right)\right] \\
+\left[0,54-0,46^{n x-2} \cos \left(\frac{2^{n x-2} \pi n}{M}\right)\right] \\
+\left[0,54-0,46^{n x-3} \cos \left(\frac{2^{n x-3} \pi n}{M}\right)\right] \\
+\left[0,54-0,46^{n x-m x} \cos \left(\frac{2^{n x-m x} \pi n}{M}\right)\right](3)
\end{gathered}
$$

Where factor $2 \pi$ represents the entire spectrum of the radian axes. The technique allows the insertion of new points in the windowing; this occurs by dividing the $2 \pi$ radian spectrum into smaller points in order to more efficiently produce a filter. This occurs with the implementation of an $n$ th polynomial applied to $2 \pi$ in addition to the 0.46 factor in order to maintain linearity.

\section{APPLICATION OF DISTORTION REDUCTION IN FIR FILTERS BY APPROXIMATION THROUGH WINDOW FACTOR ON FUNCTION COEFFICIENTS}

The development of a low-pass filter having Hamming window computationally consists in implementing a FIFO structure in which its coefficients are accumulated in the time domain and multiplied by the calculated filter coefficient (5). The example shown in Figure 2 consists of a low-pass filter having Hamming window, with cut-off frequency $1 \mathrm{~Hz}$ and sampling frequency $100 \mathrm{~Hz}$. To that filter, 136 coefficients are applied to a signal that emulates a harmonic developed by using an approximation sequence of the number $\pi$.

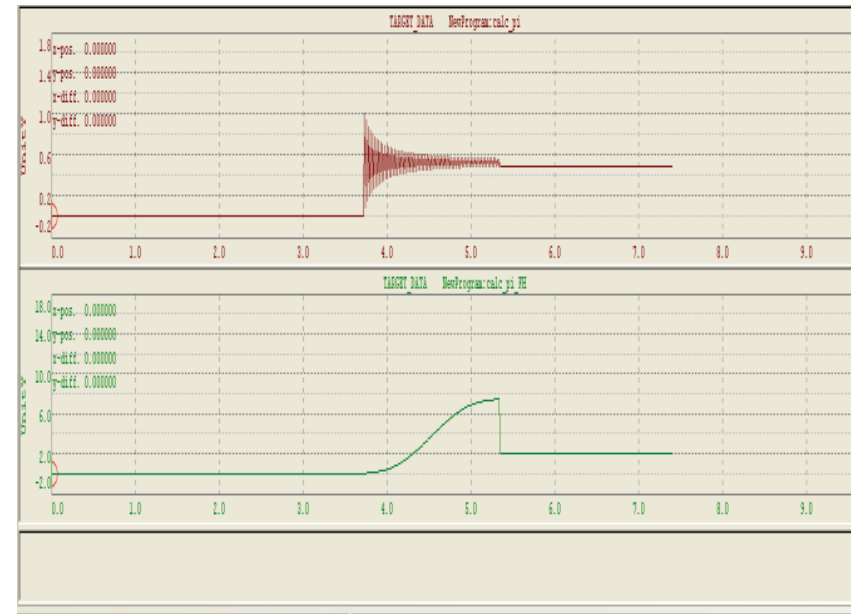

Figure 2. Filter having Hamming window in the time domain.

Figure 3 shows the same computational implementation cited in Figure 2 with the modification of the calculated coefficients according to Equation 3. This will demonstrate the increase in linearity and speed of convergence to the target point.

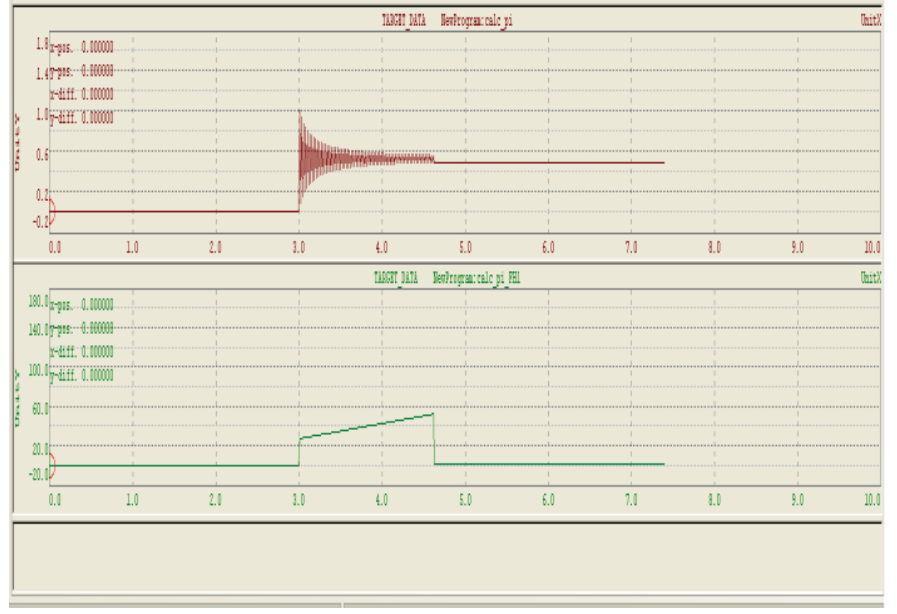

Figure 3. Filter having modified Hamming window in the time domain.

Figure 4 shows the same computational implementation mentioned in Figures 2 and 3 with a computational modification that proposes not to apply the filters to the first samples, causing the response to accelerate with respect to the target point. This effect increases the capacity of repeatability of the system by virtue of providing samples that are more stable in time.

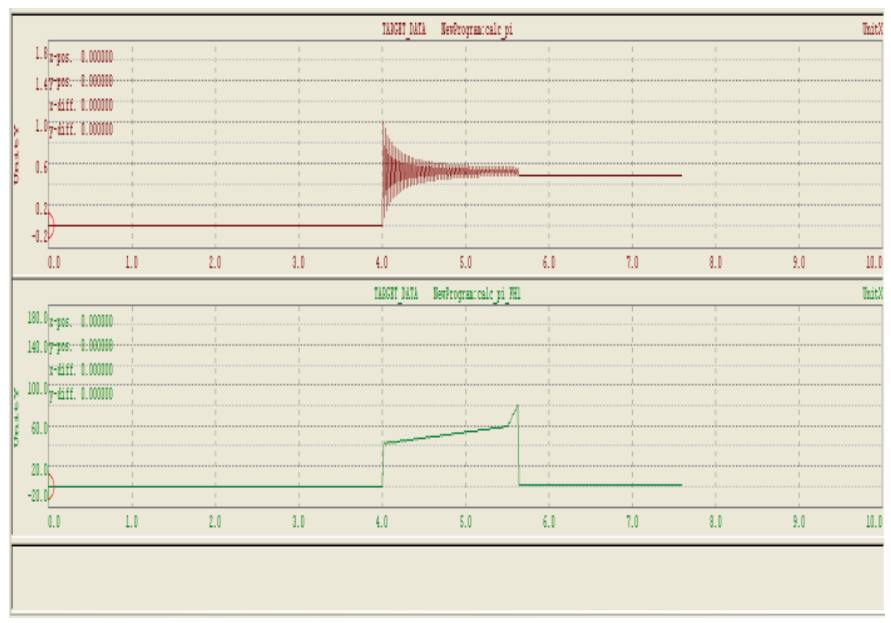

Figure 4. Filter having modified Hamming window in the time domain with computational methods.

\section{CONCLUSION}

The implementation of Equation 3 with the computational changes aiming to have a no-action rejection window of the filter causes the system to have a much more effective conversion to the target point; as a downside, it is possible to notice the occurrence of a peak at the end of the sample due to the amount of samples rejected early in the process. With the implementation of averages, this phenomenon may be easily remedied, as well as the reduction in the number of coefficients rejected by the filter early in the process.

References

[1] Adams, J.W. (1991a). FIR digital filters with least-squares stopbands subject to peak-gain constraints. IEEE Transactions on Circuits and Systems, 39, 376-88.

[2] White, S. A., "Applications of Distributed Arithmetic to Digital Signal Processing: A Tutorial Review"., IEEE ASSP Magazine, Vol. 6(3), pp.4-19, July 1989. 
[3] Bimbi, S.B. \& Fleury, A T \& Ruas, R \& Chaves, V O. (2016) Distortion Reduction in FIR Filters by Approximation through Window Factor on Function Coefficients.

[4] Adams, J.W. \&Willson, Jr., A. N. (1984). Some efficient digita prefilter structures. IEEE Transactions on Circuits and Systems, CAS-31, 260-5.

[5] Ahmed, N., Natarajan,T.\&Rao, K. R. (1974). Discrete cosine transform. IEEE Transactionson Computers, C-23, 90-3.

[6] Akansu, A. N. \& Medley, M. J. (1999). Wavelets, Subband and Block Transforms in Communications and Multimedia. Boston, MA: Kluwer Academic Publishers.

Sergio Junior Bimbi (e-mail:sergio.bimbi@fatec.sp.gov.br) is pursuing a Master's degree in Electrical Engineering (IPT) and holds a Bachelor's degree in Telecommunications Engineering from the FIEO University Center. He is currently an Electronics Engineer at Masipack and University Professor at the São Paulo State Technological College (FATEC). Sergio has experience in Electrical Engineering with emphasis in Embedded Electronics and Telecommunications, developing hardware for numerical controls, industrial automation and VHDL programming. $\mathrm{He}$ has developed research at the UNIFIEO University Center with FPGAs that are currently used in many subsequent projects. He has expertise with developing measurement systems, automatic weighing scales, PLC programming, control systems, weight checkers, digital filters for the field of measurements, etc. He develops research in the field of SDR (QPSK) with ZYNQ family integrated circuits having dynamic partial reconfiguration.

Vitor Chaves de Oliveira (e-mail: vitor.c.br@ieee.org) is a doctoral candidate in Electrical Engineering (Mackenzie), Master in Electrical Engineering (PUCC), attending specialization in Electrical Engineering and Power Systems (UNISAL), Bachelor of Computer Science (UNISAL) and Computer Technician (SENAI). University Professor working in the fields of Electrical Engineering and Computer Science; Magazine editor for the Brazilian Society of Television Engineering (SET); IT/ERP/Telecom Infrastructure Consultant at Coach IT Consulting. He is an author of books on cloud computing field and has published dozens of articles in scientific journals and at national and international conferences. His research interests are focused on Telecommunications: IP networks, Radio Broadcasting (Digital TV), Electromagnetic Theory, Control Algorithms and Mathematical Modeling of Systems.

Agenor de Toledo Fleury (e-mail: agenor.fleury@poli.usp ) Bachelor of Mechanical Engineering from ITA / Aeronautics Technological Institute (1973), Master of Mechanical Engineering from the University of São Paulo (1978) and $\mathrm{PhD}$ in Mechanical Engineering from the University of São Paulo (1985). He is currently a professor at FEI University Center, where he is Coordinator for the Mechanical Engineering Graduate Program and a $\mathrm{PhD}$ professor at the Polytechnic School of the University of São Paulo. He has experience in various projects related to Mechanical Engineering, with emphasis on Dynamic and Control Systems. His most recent projects address the modeling and control of nonlinear systems, optimal control and estimation of dynamic system states in Biomechanics, Robotics, Automotive Engineering and Embedded Systems applications. He received the SAE Brazil 2010 Engineering Education Award.
Ronaldo Ruas (e-mail: ronaldo.ruas@fatec.sp.gov.br) Bachelor's degree in Material Processes and Electronic Components from São Paulo State Julio de Mesquita Filho University (1998). Master's degree in Electrical Engineering from the University of São Paulo (2001). PhD in Electrical Engineering from the University of São Paulo (2006). Currently collaborates as a guest researcher at the integrated systems laboratory (LSI), in the plasmas and new materials field, at the Polytechnic School of the University of São Paulo. He works at Protec Brazil as a technical manager in the development of plasma-assisted thin film processes (PVD, PECVD). He teaches courses in the fields of electronics, Microprocessors and Applied Electricity at the Osasco Technological College, where he is a coordinator for the Bachelor of Industrial Automation Technology course. 